\title{
Coordination of overcurrent relays protection systems for wind power plants
}

\begin{abstract}
Wind farms are one of the most indispensable types of sustainable energies which are progressively engaged in smart grids with tenacity of electrical power generation predominantly as a distribution generation system. Thus, rigorous protection of wind power plants is an immensely momentous aspect in electrical power protection engineering which must be contemplated thoroughly during designing the wind plants to afford a proper protection for power components in case of fault occurrence. The most commodious and common protection apparatus are overcurrent relays which are responsible for protecting power systems from impending faults. In order to employ a prosperous and proper protection for wind power plants, these relays must be set precisely and well coordinated with each other to clear the faults at the system in the shortest possible time. This paper indicates how the coordination of overcurrent relays can be effectively attained for wind power plants in order to protect the power constituents during fault incidence. Through this research Matlab/Simulink as a powerful simulation software have been applied to model a wind farm and achieve precise setting for coordination of overcurrent relays.
\end{abstract}

Keyword: Overcurrent relay; Coordination of overcurrent relay; Wind power plant; Power system protection 